\title{
Multimegameter-Range Acoustic Data Obtained by Bottom-Mounted Hydrophone Arrays for Measurement of Ocean Temperature
}

\author{
Brian D. Dushaw, Bruce M. Howe, James A. Mercer, Robert C. Spindel, Fellow, IEEE, and the ATOC Group
}

(Invited Paper)

\begin{abstract}
Acoustic signals transmitted from the ATOC source on Pioneer Seamount off the coast of California have been received at various sites around the Pacific Basin since January 1996. We describe data obtained using bottom-mounted receivers, including U.S. Navy Sound Surveilance System arrays, at ranges up to $5 \mathrm{Mm}$ from the Pioneer Seamount source. Stable identifiable ray arrivals are observed in several cases, but some receiving arrays are not well suited to detecting the direct ray arrivals. At 5-Mm range, travel-time variations at tidal frequencies (about 50 ms peak to peak) agree well with predicted values, providing verification of the acoustic measurements as well as the tidal model. On the longest and northernmost acoustic paths, the time series of resolved ray travel times show an annual cycle peakto-peak variation of about $1 \mathrm{~s}$ and other fluctuations caused by natural oceanic variability. An annual cycle is not evident in travel times from shorter acoustic paths in the eastern Pacific, though only one realization of the annual cycle is available. The low-pass-filtered travel times are estimated to an accuracy of about $10 \mathrm{~ms}$. This travel-time uncertainty corresponds to errors in range- and depth-averaged temperature of only a few millidegrees, while the annual peak-to-peak variation in temperature averaged horizontally over the acoustic path and vertically over the upper $1 \mathrm{~km}$ of ocean is up to $0.5^{\circ} \mathrm{C}$.
\end{abstract}

Index Terms-Acoustic tomography, climate change.

\section{INTRODUCTION}

$\mathbf{T}$ THE ACOUSTIC Thermometry of Ocean Climate (ATOC) program has achieved its original goal of acquiring time series of acoustic travel time over basin-scale paths (Fig. 1) and using that data to accurately determine range- and depthaveraged ocean temperature [1], [2]. Acoustic sources were deployed on Pioneer Seamount near San Francisco, CA, in October 1995 and on the north slope of the Hawaiian island of Kauai in July 1997. The Pioneer Seamount site was selected to allow much of the acoustic energy to leave the source

Manuscript received July 9, 1998; revised December 29, 1998. This work was conducted as part of the Acoustic Thermometry of Ocean Climate (ATOC) and North Pacific Acoustic Laboratory (NPAL) projects supported by DARPA under Grant MDA 972-93-1-0003 and the Office of Naval Research under Grant N00014-97-1-0259.

B. D. Dushaw, B. M. Howe, J. A. Mercer, and R. C. Spindel are with the Applied Physics Laboratory, College of Ocean and Fishery Sciences, University of Washington, Seattle, WA 98105-6698 USA.

The members of the Acoustic Thermometry of Ocean Climate (ATOC) Group are A. B. Baggeroer, D. Menemenlis, C. Wunsch, T. G. Birdsall, K. Metzger, C. Clark, J. A. Colosi, B. D. Cornuelle, M. Dzieciuch, W. Munk, P. F. Worcester, D. Costa, and A. M. G. Forbes.

Publisher Item Identifier S 0364-9059(99)03037-X.

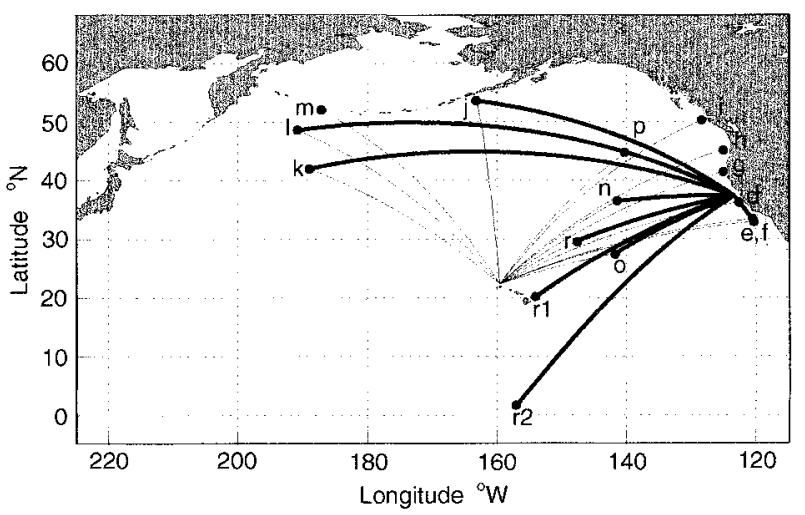

Fig. 1. The ATOC array. The array spans most of the North Pacific Ocean Acoustic paths to the various receivers from the acoustic source mounted on Pioneer Seamount off the coast of California are shown by the heavy lines, and acoustic paths from the acoustic source off the north coast of the Hawaiian island of Kauai are shown by the light lines. This paper discusses the data obtained from the Pioneer Seamount transmissions; data from the Kauai transmissions are similar.

without interaction with the ocean bottom. To date, several time series of acoustic data of about 15 months duration have been obtained from acoustic transmissions from the Pioneer Seamount acoustic source to receiving arrays located throughout the North Pacific ocean, including two moored vertical line arrays (VLA's) of hydrophones and US Navy Sound Surveilance System (SOSUS) bottom-mounted horizontal line arrays. The data have been collected since about January 1, 1996. The travel-time data are obtained in near real time, and estimates of range-averaged temperature are obtained within a few days after the data are collected. Data collected by the VLA's and data from the Kauai source transmissions are not described here.

In this paper, we review the nature of the acoustic receptions at the bottom-mounted Navy receivers with regard to their suitability for acoustic thermometry. In accordance with the requirements of the marine mammal permits associated with this particular project, the acoustic source on Pioneer Seamount will be removed in the near future, so the time series described in this paper will end. A detailed discussion of the qualities of these particular data is appropriate because of the obvious advantage of this data type for climate studies. Previous determinations of basin-scale oceanic temperature 
based on data similar to those described here have been previously reported [3]-[7]; the basic techniques reported here are certainly not new. In the present case, however, the acoustic signals employed a lower frequency $(75 \mathrm{~Hz})$ and broader bandwidth $(37.5 \mathrm{~Hz})$ than used previously for very longrange transmissions. In addition, though the acoustic source and receivers were located on the ocean bottom, nonbottominteracting ray arrivals are observed. Previous very long-range acoustic transmissions from a bottom-mounted source near Hawaii (the Kaneohe source) to bottom-mounted receivers in the northeast Pacific [3], [5] suffered from significant bottom interaction before the acoustic energy escaped to the deep ocean, which complicated the interpretation of the ray arrivals. In addition, an annual cycle of warming and cooling is apparent in the data discussed in this paper, while this cycle was not apparent in data obtained from the Kaneohe transmissions [5].

The main motivation for including Navy receivers in the ATOC array is that they are existing facilities which may be used opportunistically to measure acoustic travel times. They are stable detectors; they are cabled to shore and have expected lifetimes of the order of decades. Because these arrays are on the ocean bottom, however, they are not optimally deployed to obtain acoustic data for determining resolved-ray travel times to high accuracy. Because both the receiver arrays and the Pioneer Seamount source are bottom-mounted, the acoustic pulses frequently interact with the bottom near both the source and the receiver. In a few cases, however, some pulses or rays are upward going at the source and downward going at the receiver and so manage to avoid the ocean bottom altogether; these arrivals have provided the best data for acoustic thermometry. The bottom interactions complicate the interpretation of the received signals, sometimes severely. A further disadvantage of the use of these data is that data analysis must occur in a classified environment, and not all aspects of the data, such as the exact array locations or depths, may be discussed in the open literature.

The complexity inherent in the data obtained at the bottommounted hydrophone arrays makes these data adequate, but not optimal, for acoustic thermometry. It has been previously demonstrated that much clearer data are obtained at similar ranges when mid-water VLA's are used [8]-[10]. These other results give us confidence that the acoustic data from the bottom arrays are useful, in spite of the complications of bottom interaction.

The use of these arrays has allowed valuable data to be obtained which would not otherwise have been possible, and the data are obtained in real time. Further, the Navy receivers offer the possibility of obtaining very long acoustic time series free of the various problems (e.g., financial and logistical) associated with deploying separate instruments for the task, so that climate time-scale variations can be measured. Exploiting these national assets has proved well worthwhile.

\section{Processing of Hydrophone ARray Data}

Full-power transmissions from the ATOC source on Pioneer Seamount began December 28, 1995 [11], [12]. These irreg- ularly scheduled transmissions have a signal level of $260 \mathrm{~W}$, and they are coded using a 1023-digit $\mathrm{m}$-sequence [13] with a $75-\mathrm{Hz}$ carrier frequency. By coding the signals over a $20-$ min interval, much greater signal-to-noise ratios (SNR's) can be obtained at the receiver through signal processing, without requiring a physically louder acoustic source [7]. The precise transmission schedule is determined by the sampling requirements of the marine mammal research program (MMRP) [14]-[16], but it typically consists of four-day periods two to four times a month. Transmissions are spaced $4 \mathrm{~h}$ apart and begin on the hour at 0000, 0400, 0800, 1200, 1600, and 2000 UTC.

The raw acoustic data from each receiver array consist of time series of acoustic pressure at each of 40 hydrophones. These time series include a superposition of a multitude of the phase-coded signals from a multitude of ray arrivals, and the entire signal is buried within the dominant natural oceanic noise [17]. Data processing consists of extracting the signal out of the noise by matching the m-sequence codes and then using beamforming techniques to combine all the data from the hydrophones of the receiver array. Beamforming determines a surface of acoustic amplitude for the received signals as a function of conic beam angle and arrival time. (It is assumed that the received signals are coherent temporally over the 20-min duration of the transmissions and spatially across the 40-element hydrophone array. Work using VLA data obtained at a similar range [9], [10] suggests that only a 13-14-min coherence time is to be expected for very long-range transmissions; the bottom-mounted array data may be better processed in the future by using a shorter coherence time.) Next, the peaks in the amplitude surface are selected, together with their associated conic angle and a travel time. These selected data, some of which may be identified with ray arrivals, are then displayed using what we denote as a "dot plot" (Fig. 2). Because only the conic angle is resolved by beamforming, the vertical ray arrival angle can be determined only by using the known angle for the bearing of the arriving acoustic signal with respect to the orientation of the hydrophone array.

\section{RECEPTIONS AT BOTTOM-MOUNTED HYDROPHONE ARRAYS}

The dot plots for the receptions at the bottom-mounted hydrophone arrays are more complex than those for sources and receivers in the middle of the water column [8]-[10]. The nature of the acoustic energy arriving at each array is different. The main goal in processing these receptions is to extract time series of discrete, resolvable, and identifiable ray arrivals. It is these time series that are used to derive estimates of the oceanic thermal variability. The arrival patterns at the various receivers are discussed next, and subsequent sections discuss ray identification and the extraction of travel-time series from these data. Only data obtained at SOSUS arrays $\boldsymbol{k}, \boldsymbol{l}, \boldsymbol{n}, \boldsymbol{o}, \boldsymbol{p}$, and $\boldsymbol{j}$ using transmissions from the Pioneer Seamount acoustic source (Fig. 1) are discussed in this paper. 
(a)
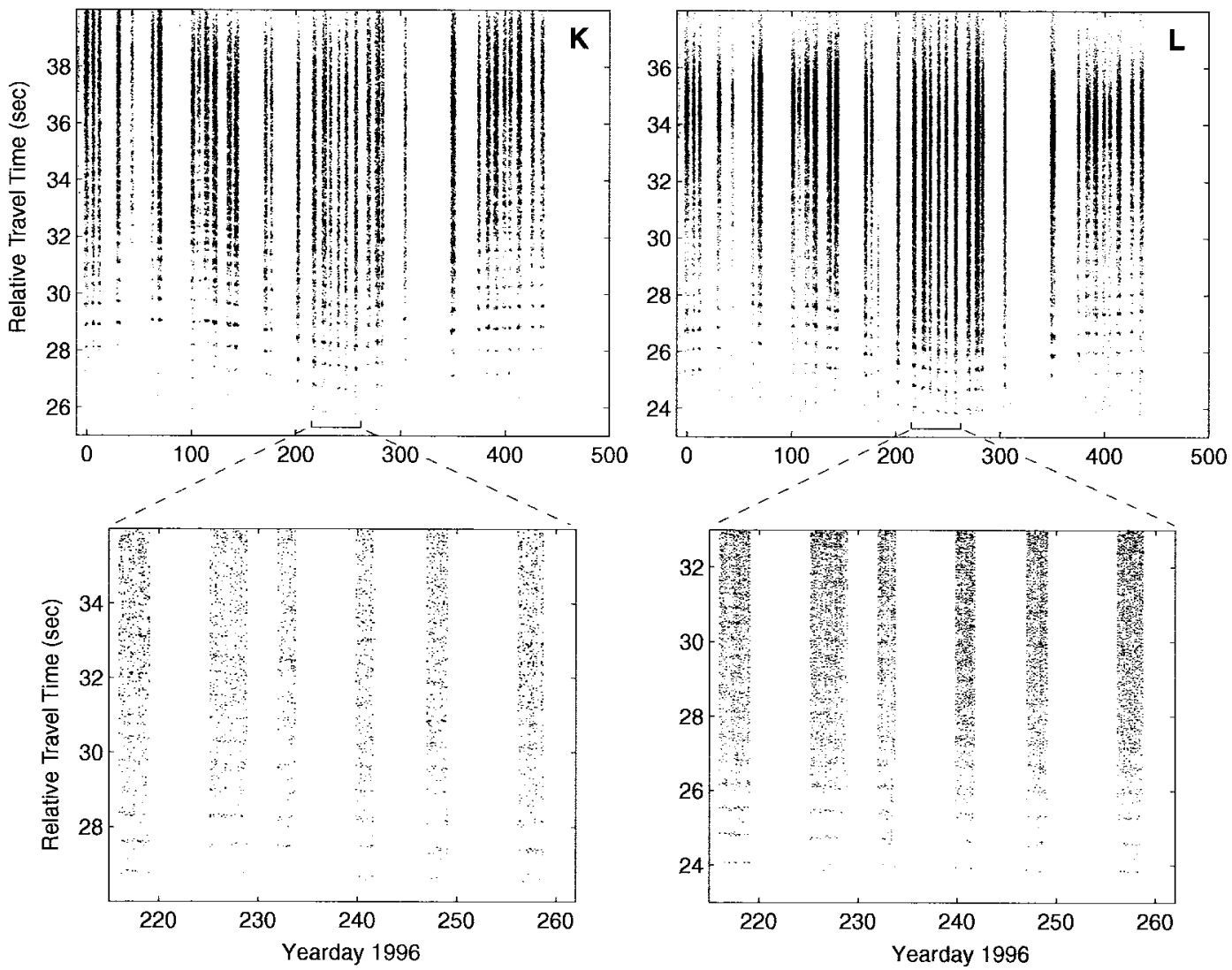

Fig. 2. Acoustic receptions at receivers $\boldsymbol{k}$ and $\boldsymbol{l}$. (a) The entire time series obtained. (b) A closer view of small sections of the time series as indicated. Dot size is proportional to SNR. Stable ray arrivals are evident, and an annual cycle is evident in the travel-time variations. See Fig. 5 also.

\section{A. Direct Ray Arrivals at 5-Mm Range: Arrays $\boldsymbol{k}$ and $\boldsymbol{l}$}

Several stable ray arrivals are evident in the arrival patterns at 5-Mm range (Figs. 2 and 5). In the receptions at $\boldsymbol{k}$, about a dozen or so ray arrivals are evident, and these show a clear annual cycle with travel times that decrease with warming water in summertime and increase again with cooling water in winter. In the receptions at $\boldsymbol{l}$, only a few ray arrivals are evident, and these show a variation with an annual period similar to that observed at $\boldsymbol{k}$. A month-long gap in the time series around yearday 325 is due to equipment failure.

Close inspection of these arrivals (Fig. 2), however, shows that often the best arrival (or "dot") to choose in order to derive a time series of ray travel times is not obvious (see Section V). This problem is partly caused by acoustic scattering from the ocean bottom near the bottom-mounted acoustic source and receiver. The earlier ray arrivals suffer much less from the noise of bottom-interacting energy. As the arriving acoustic energy scatters off the ocean bottom, it becomes a source of noise for the later arriving rays. The full arrival pattern is a superposition of direct nonbottom-interacting rays and noise caused by the scattering of acoustic energy from the ocean bottom near the source or receiver. The complexity in the receptions does not preclude the use of these data for oceanic observation, however. The complexity causes the derived time series to have more high-frequency variability $(>1 \mathrm{cpd})$, but there are sufficient data that the low-frequency travel times $(<1 \mathrm{cpd})$ have an uncertainty of only $10 \mathrm{~ms}$ (this will be discussed more later).
One unresolved issue is why the receptions appear to fade out on some days. These fade outs are apparently not related to ambient noise near the hydrophone arrays; time series of ambient sound collected at these sites by Curtis et al. [17] show no apparent correlation with these fade outs. A varying SNR might be related to environmental influences (e.g., the movement of oceanic fronts?) on the acoustic propagation.

\section{B. Receptions at Deep Receivers: Arrays $\boldsymbol{n}$ and $\boldsymbol{o}$}

The receivers $\boldsymbol{n}$ and $\boldsymbol{o}$ are located in deep water midway between Pioneer Seamount and Hawaii, and they provide data with an interesting interpretation but with considerable variability. As in the receptions at $\boldsymbol{k}$ and $\boldsymbol{l}$, the bottominteracting acoustic energy sometimes makes it difficult to discern the acoustic energy arriving directly (Figs. 3 and 6). However, it has still proved possible to determine time series of ray arrivals, albeit with some difficulty.

As will be further discussed in a subsequent section, some of the resolved arrivals at these deeper arrays represent an interesting, and perhaps new, type of "ray" arrival which appears to occur well into the shadow zone of the predicted arrival. We will refer to these arrivals as "shadow-zone arrivals" [18]. While all of the stable arrivals can be associated with a cusp of the predicted time front, the later arrivals are $500-1000 \mathrm{~m}$ below the predicted time front. (A "time front" is the pattern of the acoustic energy arriving at the receiver range as a function of travel time and depth.) These shadow-zone arrivals appear to retain "ray-like" aspects, but the latest arrivals, or those 
(a)
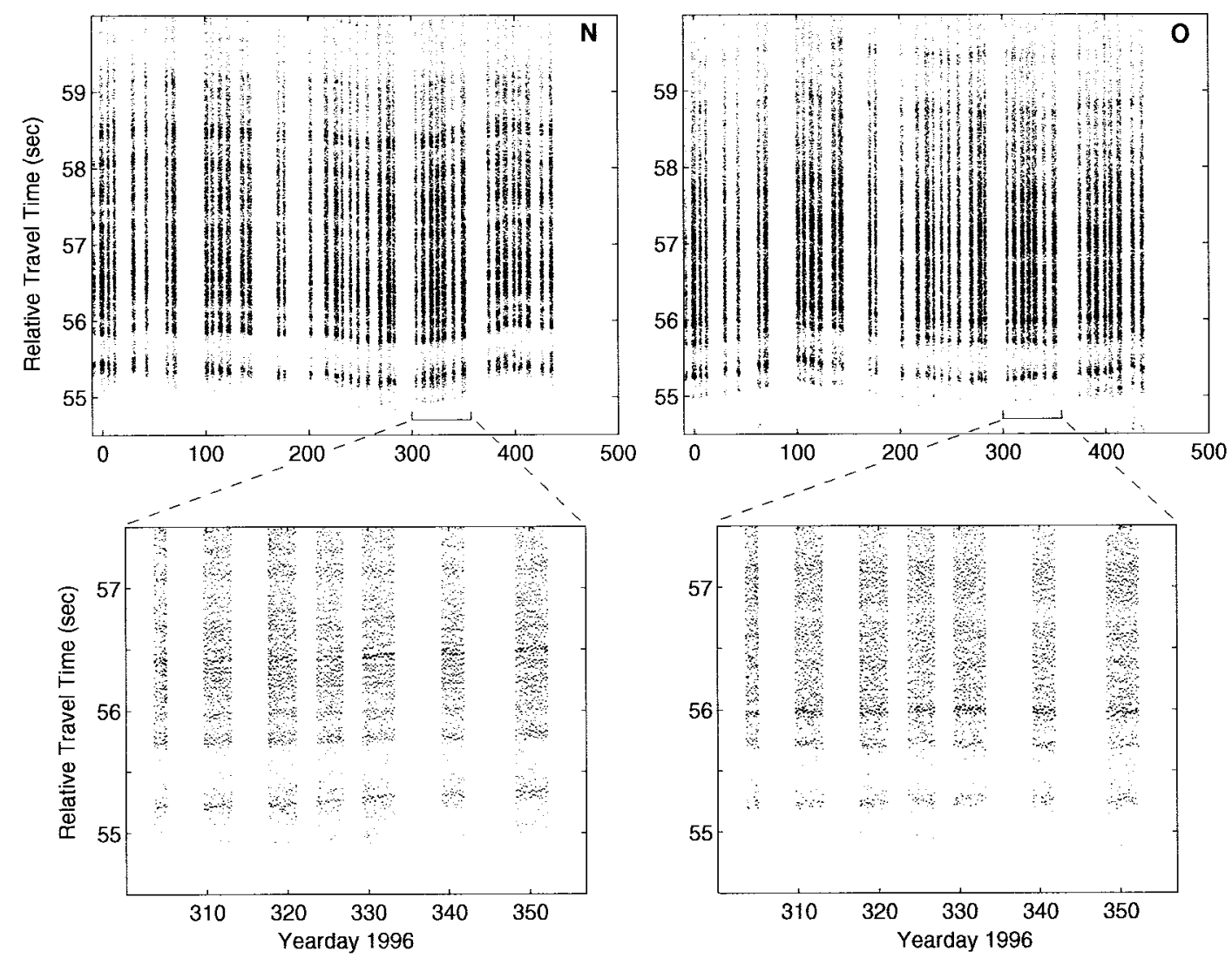

Fig. 3. Same as Fig. 2 but for acoustic receptions at receivers $\boldsymbol{n}$ and $\boldsymbol{o}$. (a) the time series as indicated. See Fig. 6 also.

deepest into the shadow zone, are certainly less distinct. The shadow-zone arrivals appear to be stable, and so travel-time time series can be derived from them. Indeed, the apparent stability of these arrivals, together with the detection of similar arrivals at several other deep arrays in both the Atlantic and Pacific oceans, rules out bottom interaction as the origin of these arrivals. To date, no known mechanism, e.g., diffraction leakage from the caustics or diffusion of acoustic energy by internal wave scattering, can explain the extreme depth diffusion of acoustic energy that must be occurring.

Because the forward problem for the shadow-zone arrivals is unknown, it is not known how to apply these data correctly to determine ocean temperature changes. For the time being, the ray paths predicted for the time front cusp will be used to represent the sampling associated with these arrivals, even though the time front cusp may be several hundreds of meters above the receiver depth.

\section{Problematic Data: Arrays $\boldsymbol{j}$ and $\boldsymbol{p}$}

Although useful data have been obtained at hydrophone arrays $\boldsymbol{k}, \boldsymbol{l}, \boldsymbol{n}$, and $\boldsymbol{o}$, the data obtained at some arrays have not yet proved useful. Most of the acoustic energy arriving at receivers $\boldsymbol{j}$ and $\boldsymbol{p}$ (Fig. 4) has probably undergone considerable interaction with the ocean bottom either near the acoustic source or receiver or somewhere along the acoustic path, so that much of the arriving energy has lost all obvious relation to the incoming acoustic rays. Note, however, that this energy is still coherent in that the integrity of the $m$-sequence coding is apparently retained. The acoustic arrivals at receiver $\boldsymbol{j}$, for example, show minimal evidence of stable ray arrivals. Hints of travel-time variation with an annual cycle are apparent in the dot plot for receiver $\boldsymbol{j}$, but it has not proved possible to extract a time series with any reliability. A stable arrival pattern is evident for receiver $\boldsymbol{p}$, but only the first pair of arrivals occurs at times that may possibly be identified with predicted arrivals. Ray identification using only two arrivals is marginal; as will be discussed in the next section, the unique dispersal pattern of the arrivals is an important property that gives us confidence in the identification.

Arrays $\boldsymbol{j}$ and $\boldsymbol{p}$ are probably situated such that clear acoustic paths do not exist between the source and receiver. For example, the Mendocino Escarpment along $40^{\circ} \mathrm{N}$ has topographic features that rise to a depth of about $2000 \mathrm{~m}$, and these features may block some of the acoustic paths. As is the case for some of the arrivals at receivers $\boldsymbol{n}$ and $\boldsymbol{o}$, unless the forward problem can be understood, it is not obvious how to use these time series to solve for oceanic variability.

\section{Absolute Travel Times and Ray Identification}

In order to use travel-time data to measure variability in oceanic sound speed (temperature), the resolved arrivals need to be identified with predicted ray arrivals and their associated ray paths. In addition, extraction of time series of ray travel times from the "dot plots" is aided when the predictable arrivals in the receptions are identified. Predicted ray arrivals are found by using an acoustic propagation code together with 
(a)
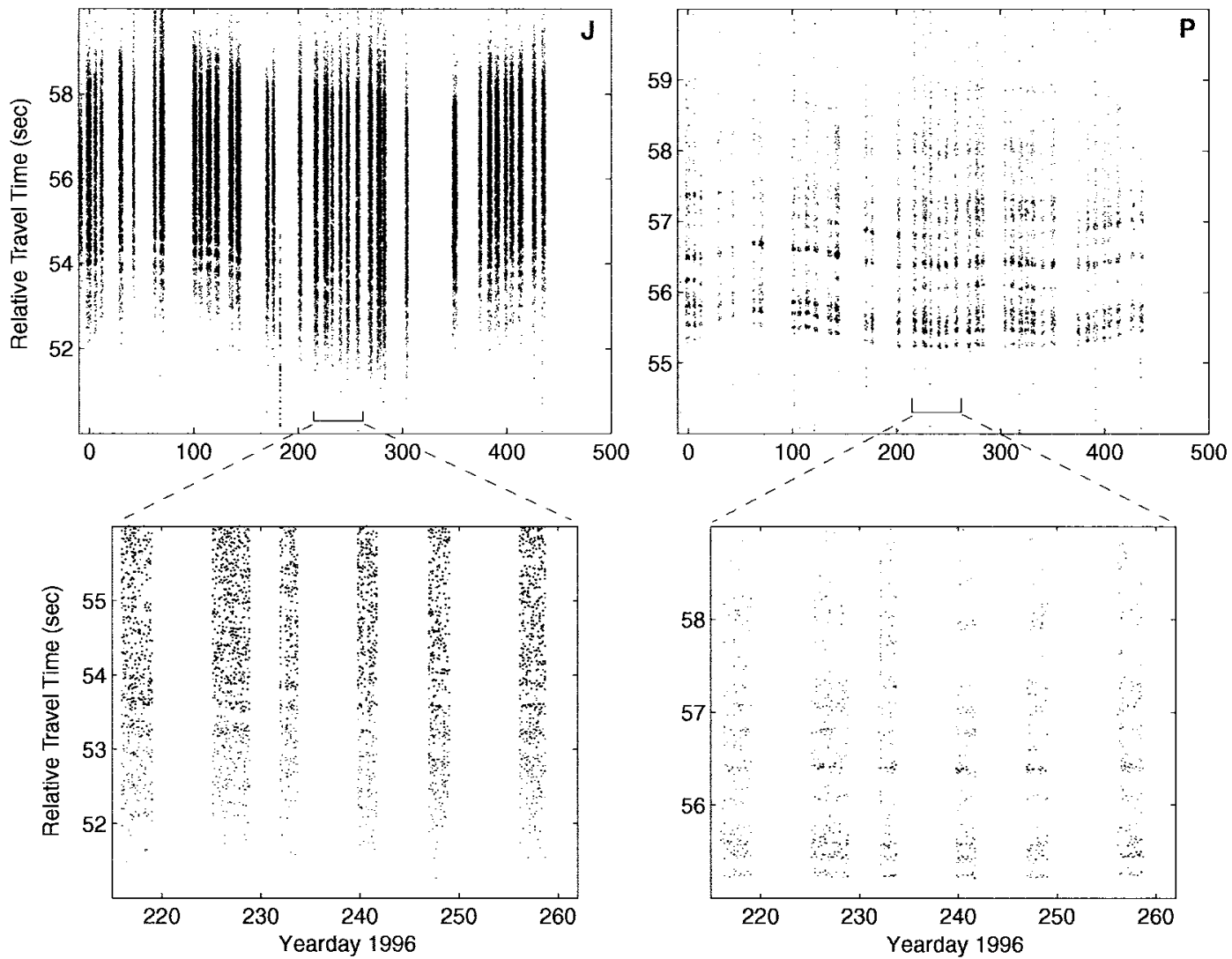

Fig. 4. Acoustic receptions at receivers $\boldsymbol{j}$ and $\boldsymbol{p}$. (a) The entire time series obtained. (b) A closer view of small sections of the time series as indicated. These receptions show that clear, resolvable ray arrivals may not always be available at any given receiver. Transmissions to these receivers may be partially blocked by topographic features.

an estimate of the sound-speed field between the acoustic source and the receiver. This is the "forward problem" in ocean acoustic tomography; in the inverse problem, the resolved ray paths are used to solve for the oceanic sound-speed variability using the ray travel times. (We do not consider individual acoustic mode arrivals on the bottom-mounted receivers, although the ray arrivals may be reconstructed using a set of modes to high order $\mathrm{O}(100)$. However, even if it were possible to separate all of these high-order modes in a reception at $5-\mathrm{Mm}$ range, the receiver does not have the depth resolution needed to separate all these mode arrivals. The lowest mode arrivals are hopelessly lost in the din of bottom-interacting energy that appears in the latter part of the reception.) Accurate ray identification is thus critical. While it was not obvious in advance that multipath arrivals at a bottom-mounted array from a bottom-mounted acoustic source $5 \mathrm{Mm}$ distant could be identified, most of the stable arrivals at arrays $\boldsymbol{n}, \boldsymbol{o}$, and $\boldsymbol{k}$ have been uniquely identified. The basic properties of the predicted acoustic rays and their travel times are not sensitive to small variations in the sound-speed field used to make the predictions, even for a $5-\mathrm{Mm}$ propagation range.

Although the acoustic scattering from the ocean bottom is clearly an important effect for the receptions considered here, we do not feel that the topography near the arrays is known well enough for accurate predictions. Therefore, all of the ray predictions described here do not include a model for the ocean bottom. Predictions which include the topographic effects do not affect the conclusions.

We used the RAY computer code [19], [20] to predict the expected ray arrival pattern by ray tracing. The path from the acoustic source to the acoustic receiver is taken as a geodesic on the WGS84 ellipsoid [21], and the ray trace is twodimensional in range and depth. The range and path between the source and receiver are calculated using a method derived by Dworski with an estimated accuracy better than $1 \mathrm{~m}$ for a 5Mm range [22]. Horizontal refraction of the ray paths has not been considered here, but this is expected to be quite small [6], [23].

The location of the Pioneer Seamount source was accurately surveyed using GPS positioning. The source position is accurate to about $\pm 4 \mathrm{~m}$ horizontally and about $2 \mathrm{~m}$ vertically [12]. The receiver positions are assumed to be accurate to within a few tens of meters since they were surveyed using GPS. Thus, errors in the positions of the instruments should not adversely affect the ray predictions.

In order to test the robustness of the prediction, we have used the Levitus82 [24] and Levitus94 [25], [26] ocean atlases to calculate climatological models for the ocean sound-speed field. Sound speed is calculated using the Levitus depth, temperature, and salinity. First, the pressure corresponding to depth, temperature, and salinity is calculated, and then sound speed is calculated using the Del Grosso sound-speed equation [27]-[30]. Sound-speed profiles at points along the path from 
the source to the receiver are required for ray tracing. The choice of the method used to interpolate between the 33 standard Levitus depths is important to avoid adding biases or unphysical structure to the sound-speed profile. The ray predictions here used the vertical interpolation inherent in the RAY code; these results closely matched those using a cubic spline vertical interpolation. The best means of interpolation is ambiguous, however. The Levitus data were horizontally interpolated using a cubic spline onto points at about 100$\mathrm{km}$ range increments on the path from the source to the receiver.

The predicted travel times will be compared to the travel times averaged over the 15 months of available data. The measured arrivals are identified with the predicted ray arrivals by using the dispersal, or spacing, of the arrivals. Sound-speed models such as the Levitus atlas cannot be used to predict the absolute travel times accurately. Differences between the measured and predicted absolute travel times of $\mathrm{O}(1 \mathrm{~s})$ can be expected because of the temperature differences between the Levitus models and the true ocean. The dispersal of the arrivals has always proved to be a unique pattern in the past, however.

\section{A. Identification of Receptions at Arrays $\boldsymbol{k}$ and $\boldsymbol{l}$}

For receptions at $k$ [Fig. 5(a)], there is only one alignment for which all the measured and predicted arrivals correspond. The resolved and identified rays at this northern array are all refracting-surface-reflecting (RSR) and have typical lower turning depths between 2500 and $3500 \mathrm{~m}$. Since the acoustic paths traverse high latitudes, where the ocean has near-adiabatic sound-speed profiles, surface reflecting rays are expected. The vertical ray angles with respect to the horizontal near the source and receiver vary from $8^{\circ}$ to $10^{\circ}$. The identified rays are all upward going at the bottom-mounted acoustic source and downward going at the bottom-mounted receivers, a fact which gives us some confidence as to the ray identification. The ray arrivals derived from Levitus 82 and Levitus94 have nearly identical dispersal, though the absolute travel times differ by about $85 \mathrm{~ms}$ (Levitus94 is slightly colder than Levitus82). The data convey primarily one piece of information: the range- and depth-averaged temperature.

For $k$, the measured travel times averaged over the 15 months of available data and the predicted travel times using the annual-mean Levitus 94 atlas differ by $200-220 \mathrm{~ms}$ [Fig. 5(a)]. The measured travel times are greater than those predicted. The measured and predicted travel times may differ because the "true" ocean is colder than the ocean model used to make the predictions. Alternatively, the travel-time differences may be due to a small error in the Del Grosso sound-speed equation at high pressures [10].

It has not proved possible to identify the "ray" arrivals at array $\boldsymbol{l}$ [Fig. 5(b)], however, even though this array is near the array $\boldsymbol{k}$. The weak SNR and small number of resolved ray arrivals make the ray arrivals less obvious. The identification that best associates the temporal dispersal of the measured and predicted arrivals for $\boldsymbol{l}$ results in a 4-s offset between the predicted and measured travel times and uses predicted rays that are far too steep to be realistic. In addition, for these

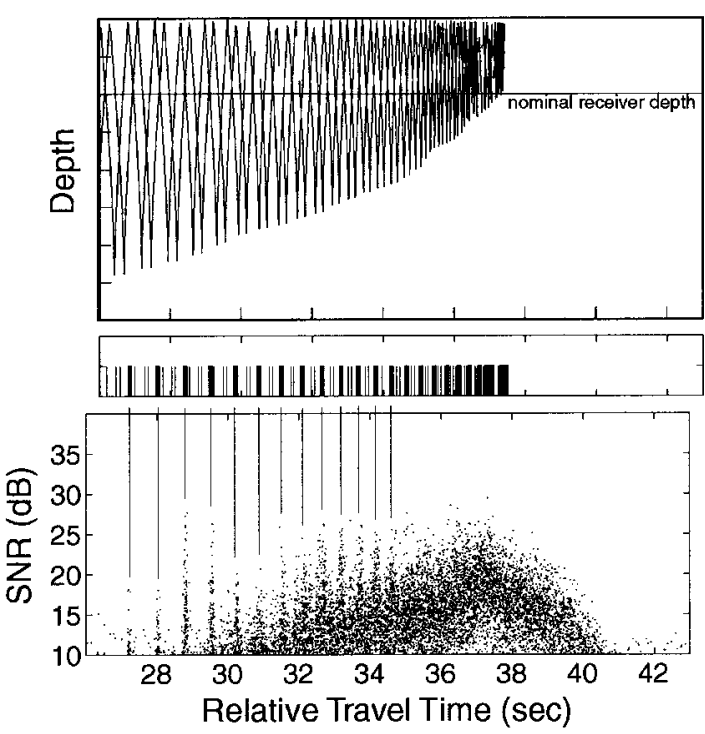

(a)

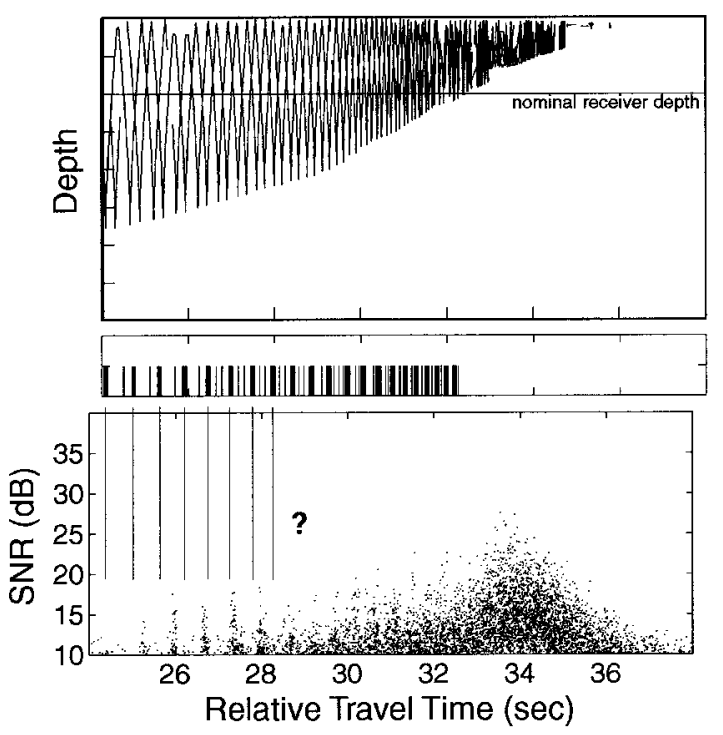

(b)

Fig. 5. Identification of ray arrivals at (a) $\boldsymbol{k}$ and (b) $\boldsymbol{l}$. The bottom panel of (a) shows the SNR versus the travel times of the data selected after beamforming, i.e., the "dots" from the "dot plots" of Fig. 2, using data from several receptions. The top panel of (a) shows the predicted time front. The middle panel of (a) shows the receptions predicted at the nominal receiver depth, with the identified arrivals noted by the heavy lines. The observed ray arrivals correspond to the heavy lines in the middle panel and also mark the rays which leave upward from the bottom-mounted source and arrive downward at the bottom-mounted receiver. The dispersal, or spacing, of the arrivals is unique for array $\boldsymbol{k}$, so the identification of the ray arrivals is unambiguous. Ray identification appears not to be possible for array $\boldsymbol{l}$.

steep rays, the annual cycle (see Section VIII-C) in travel time predicted from the monthly Levitus atlas has an amplitude that is too small compared to the results at $\boldsymbol{k}$ and the observed travel-time variation at $\boldsymbol{l}$. Thus, we conclude that no obvious ray identification is available for the receptions at receiver $l$. The alignment shown in Fig. 5(b) is based on the assumption that the offset between measured and predicted arrivals is equal to that of $k$. Possible errors that may be introduced by the misidentification of the rays at receiver $\boldsymbol{l}$ are minimal because of the similarity in sampling of all these rays. Bottom scattered 


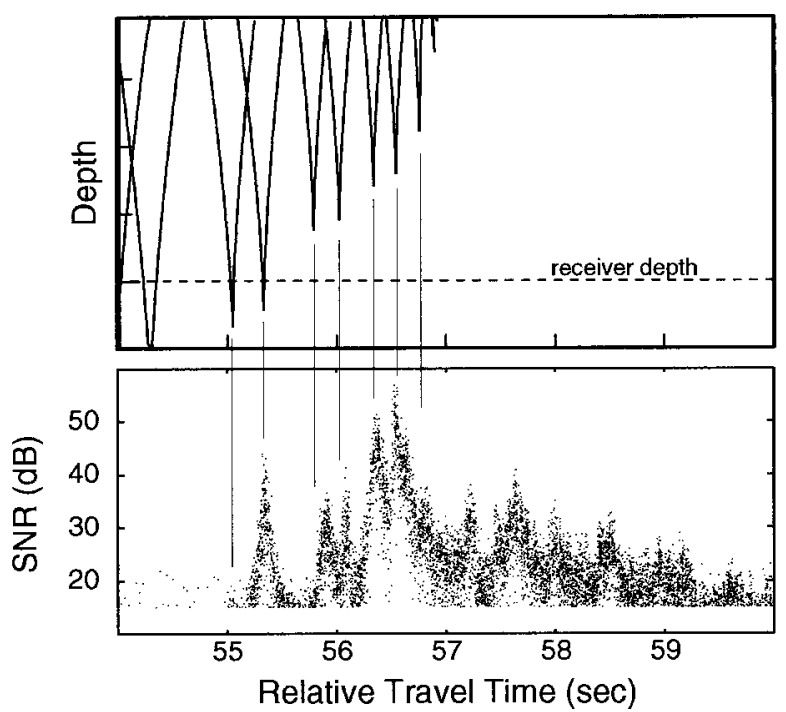

(a)

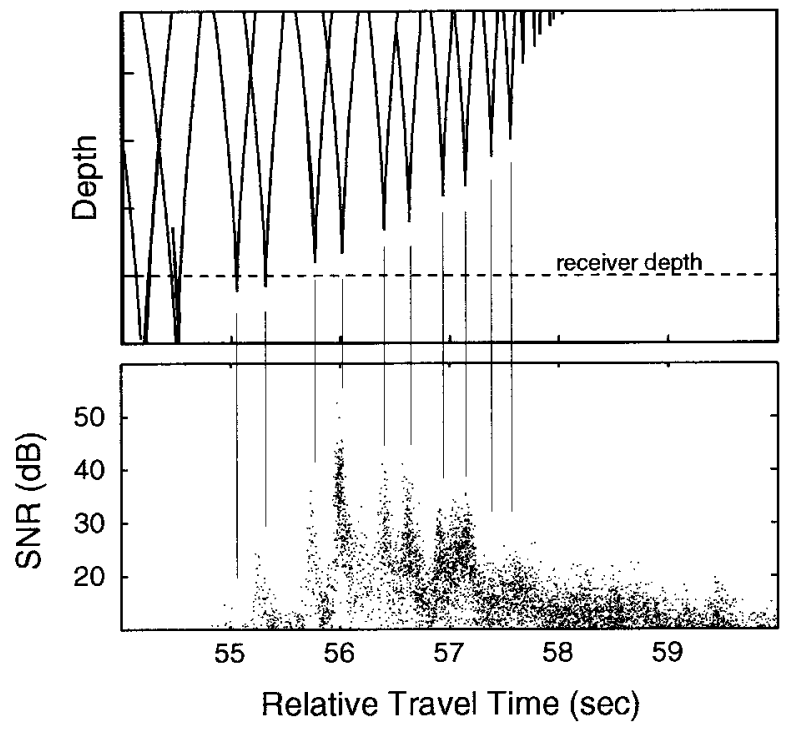

(b)

Fig. 6. Same as Fig. 5 but for ray arrivals at (a) $\boldsymbol{n}$ and (b) $\boldsymbol{o}$. No offset is applied to align these measured and predicted arrival patterns. While the dispersal of the ray arrivals is unique as for $\boldsymbol{k}$ and $\boldsymbol{l}$, the later arrivals are unexpected because the depth of the receiver is several hundred meters below the deepest parts of the predicted arrival pattern. The observed arrivals appear to be identified with the cusps, or caustics, of the predicted time front.

energy is evident in the jumble of acoustic energy that is observed for several seconds after the latest predicted arrival.

\section{B. Identification of Receptions at Arrays $\boldsymbol{n}$ and $\boldsymbol{o}$}

The ranges to arrays $\boldsymbol{n}$ and $\boldsymbol{o}$ are significantly less than those to $\boldsymbol{k}$ and $\boldsymbol{l}$; hence, the identification of the ray arrivals is more obvious because the effects of the difference between our assumed and "true" oceans has less effect on the travel times at shorter range. Given the magnitude of expected oceanic variations, we expect that the measured and predicted travel times will differ by at most a few hundred milliseconds, and indeed the identification is obvious at $\boldsymbol{n}$ and $\boldsymbol{o}$ [Fig. 6(a) and (b)]. As was the case for the identification of receptions at $\boldsymbol{k}$, the dispersal of the arrivals is unique and the measured and predicted arrivals are uniquely associated. Bottom-interacting acoustic energy is evident in the later portion of the measured arrival pattern.

While there is an obvious one-to-one correspondence between measured and predicted arrivals, the later arrivals appear to occur well into the shadow zone of the predicted arrival pattern. In other words, for the latest arrivals, the receiver depth is several hundred meters below the deepest extent of the predicted rays. This result is surprising, and no currently available theory accounts for this anomalously deep acoustic energy.

In terms of their suitability for acoustic thermometry, these anomalous "shadow zone" arrivals present a dilemma. On the one hand, they appear to be stable identifiable arrivals, while, on the other hand, the forward problem is not known, so legitimate inversion of these data is not possible. As described previously, we assume that the ray paths appropriate for these arrivals are those associated with the cusp in the time front with which the arrivals are identified, and we furthermore assume that the observed travel time variations are linearly related to the sound-speed changes along these ray paths. The latter assumption seems reasonable because the travel-time variability of the "shadow zone" arrivals is hardly different than that of the direct arrivals, as would be expected in the dispersal of direct arrivals at this range. In addition, the identification of "shadow zone" arrivals with the cusps of the time fronts shows an obvious relation between the predictions and the measurements. These assumptions will have to be verified by additional research, however.

\section{Tracking the Time Series of Ray ARrivals}

The time series of resolved-ray travel times are derived from the dot plots by "tracking" the stable arrivals, i.e., by selecting the small subset of dots that regularly appear in each reception. The computer program that tracks the arrivals uses a template defined by travel time and conic angle. The arrivals selected are those that best line up with this template. A Gaussian weighting scheme is used to take into account the SNR of the arrivals, together with travel time and arrival angle misfits with the template. The template is allowed to evolve slowly from one reception to the next to account for natural evolution in the ray arrival pattern, but considerable persistence to the template is enforced [30]. While the tracking procedure is automated to a large extent so that the tracked data are statistically consistent from one part of the time series to the next, considerable human intervention is required to correct for obvious errors in dot selection. Tracking of the individual ray arrivals is significantly improved when arrivals at conic angles other than the expected angle are removed.

The integrity of the tracked time series can be examined by overlaying it on the dot plots (Fig. 7). Some of the problems with accurately deriving tracked time series are: 1) bottomscattered acoustic energy introduces considerable complexity in the receptions so that the selection of the correct "dot" in any particular reception is not always obvious; 2) sometimes the receptions suffer a decrease in SNR for some unknown, 

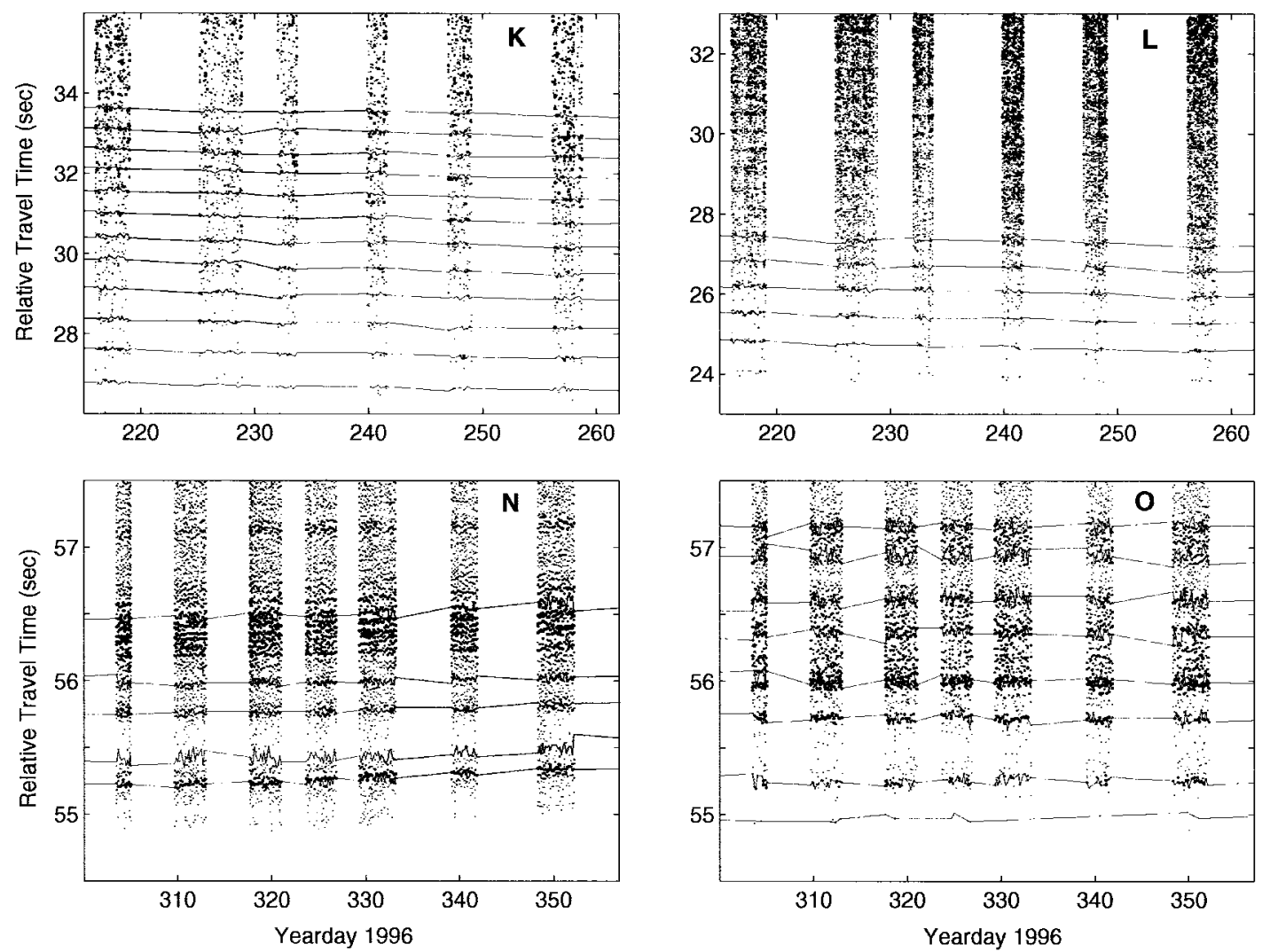

Fig. 7. A small subset of time series showing tracked data for data obtained at arrays $\boldsymbol{k}, \boldsymbol{l}, \boldsymbol{n}$, and $\boldsymbol{o}$. It is not always obvious which "dot" should be selected in each received transmission, but sufficient data are available to determine time series adequate for acoustic thermometry.

but probably natural, reason; and 3) it is sometimes difficult to ensure that the same ray arrival is tracked across gaps in the time series resulting from the marine mammal transmission schedule or equipment failures. Despite these difficulties, we are reasonably confident that the integrity of the derived time series is adequate for reasons to be described in subsequent sections.

\section{High-FreQuency TraVel-Time VARIANCES}

For the purpose of this paper, the variances of the highpass-filtered time series of the resolved-ray arrivals are used to quantify the noise in the low-pass-filtered travel times. These variances are caused by a variety of factors such as ambient acoustic noise, errors in the selection of the correct ray arrival during tracking, tidal variability, and internal-wave-induced travel-time fluctuations.

The resolved-ray travel times are high-pass-filtered by subtracting the average travel times over each two- or four-day transmission period. The high-frequency variances of the ray travel times are typically $500-1000 \mathrm{~ms}^{2}$, with about $400 \mathrm{~ms}^{2}$ of that accounted for by the barotropic tidal currents (Table I). The measured nontidal variance can be partially attributed to internal waves, but the dominant contribution is probably caused by the complexity in the dot plots and the inability to distinguish the apparent multiple arrivals for each ray when the data are tracked.

Many investigators have been concerned with the precise quantitative description of the effects of internal waves on
TABLE I

High-Frequency ( $>1$ cpd) Travel-Time Variances. Because Some Ray ARrivals are Clearer Than Others, a Wide Range of Variances is Observed. The "EXPected Variances" are Rough Estimates Based on a Crude Model for Travel-Time Variations Caused by Internal Waves. The "Tidal Variances" are Predicted Using the TPXO.2 Tidal Model. The Path to Receiver $\boldsymbol{n}$ Is Along the Minor Axis of the Tidal Currents; Hence, the Tidal Variance Associated with that Path is Small

\begin{tabular}{ccccc} 
receiver & $\begin{array}{c}\text { approximate } \\
\text { range } \\
(\mathrm{Mm})\end{array}$ & $\begin{array}{c}\text { observed } \\
\text { variance } \\
\left(\mathrm{ms}^{2}\right)\end{array}$ & $\begin{array}{c}\text { expected } \\
\text { variance } \\
\left(\mathrm{ms}^{2}\right)\end{array}$ & $\begin{array}{c}\text { tidal } \\
\text { variance } \\
\left(\mathrm{ms}^{2}\right)\end{array}$ \\
\hline & & & & \\
k & 5 & $560-840$ & 500 & 400 \\
I & 5 & $450-1660$ & 500 & 400 \\
n & 1.5 & $200-800$ & 150 & 5 \\
0 & 2 & $500-1000$ & 200 & 50 \\
& & & & \\
\hline
\end{tabular}

acoustic ray travel times [32]. Manifestations of these effects include (nontidal) high-frequency $(>1 \mathrm{cpd}$ ) variability of the ray travel times $[\mathrm{O}(12 \mathrm{~h})$ slow wander to $\mathrm{O}(10 \mathrm{~min})$ rapid variations] and a small bias in the mean travel time. For the reasons described above, the variances observed here are larger than those expected from internal wave effects alone (Table I). Munk et al. [7] describe the rough formulas to estimate the 

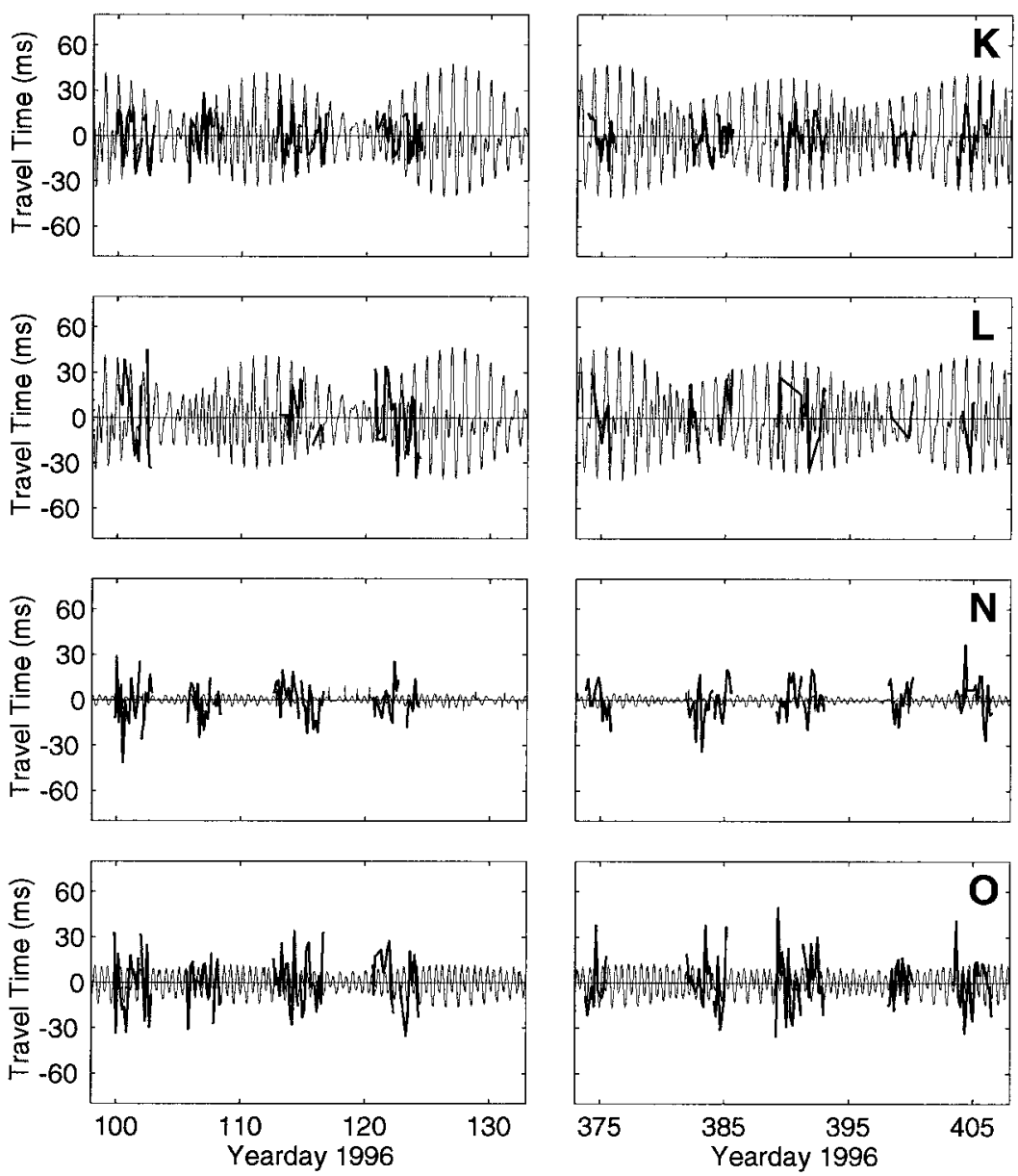

Fig. 8. Comparison of measured high-frequency ( $>1 \mathrm{cpd}$ ) variability at arrays $\boldsymbol{k}, \boldsymbol{l}, \boldsymbol{n}$, and $\boldsymbol{o}$ with tidal predictions using the TPXO.2 global tidal model. The data result from the average of the several ray travel times determined from each transmission. The tidal variations in the travel times result from the tidal currents. Good agreement in both amplitude and phase is frequently observed, but considerable noise is evident in the travel-time time series.

variance associated with travel-time wander; these formulas give travel-time variances of about $100 \mathrm{~ms}^{2}$ per megameter for refracted rays (surface-reflected rays are less affected by internal wave noise because they quickly pass through the depths where internal wave variability is greatest).

The uncertainty in the low-frequency travel times is given by the high-frequency variances divided by the number of travel times used to calculate the average over a transmission period. Thus, for the first ray arrival at array $\boldsymbol{k}$ which has a high-frequency variance of about $800 \mathrm{~ms}^{2}$, the uncertainty in the low-frequency travel times would be about $\sqrt{800 / 24}=$ $6 \mathrm{~ms}$ for a 4-day transmission period with 4-h sampling. In this case, data noise is a negligible contribution to the uncertainty in the final temperature estimates. The temperature uncertainties result almost entirely from the limited resolution of the modeled oceanic variability. The available data and their associated ray paths do not allow all of the modeled oceanic variability to be resolved [2].

\section{PREDICTIONS OF TIDAL VARIABILITY}

A tidal variability is clear in the high-frequency travel times when the travel times for the several resolved ray arrivals in each reception are averaged. The ray-averaged highfrequency time series can be compared with the predicted tidal signal derived from the barotropic tidal currents of the TPXO.2 tidal model [33]. Prediction of tidal variations in megameter-range acoustic travel times has been described previously [34]. Headrick et al. [35] and Dushaw et al. [36] describe other comparisons between predicted tidal variability and tidal variability determined using long-range acoustic transmissions.

While the ATOC time series obtained to date are too irregular to derive meaningful tidal harmonic constants, the degree to which the TPXO.2 model can predict the tidal variability observed in the long-range transmissions provides both a measure of the accuracy of the TPXO.2 model and a test of the integrity of the acoustic data. Internal-tide variability [36], [37] may make the prediction of the total tidal variability in the one-way transmissions impossible at shorter ranges, but for the long acoustic paths considered here (5-Mm range), the internal-tide "noise" should be reduced by the averaging inherent in the measurement.

On the $5-\mathrm{Mm}$ paths to $k$ and $\boldsymbol{l}$, the tidal variability in the high-frequency time series appears to be accurately predicted by the TPXO.2 model (Fig. 8). The good agreement evident between the two time series demonstrates the ability of the TPXO.2 model to accurately predict tidal variability in averages over megameter ranges. This comparison is sensitive to 
the tracking; as can be seen, the comparison is good much of the time but poor at other times (this is particularly apparent in the comparison with the receptions at $\boldsymbol{l}$ when the SNR is weak). However, the good agreement overall is a successful test of the acoustic measurements as well as the TPXO.2 model.

Tidal variations are not evident in the travel times to arrays $\boldsymbol{n}$ and $\boldsymbol{o}$ (Fig. 8). The predicted tidal variability in the data obtained at these arrays is quite weak, and these data suffer from considerable noise presumably introduced by bottom interactions or by the nature of the "shadow-zone" arrivals.

A favorable comparison of measured and predicted tidal variability is one step toward concluding that the acoustic data collected from transmissions over a 5-Mm range are adequate for oceanographic observation. This comparison shows that individual arrivals can be tracked and that the information about ocean tides is conveyed in the time series of travel times. The comparison shows that even at 5-Mm range the acoustic signals have not been excessively scrambled by internal-wave variability, "ray chaos" [7], or the interaction of acoustic energy with the ocean bottom. However, the tides are large-scale and barotropic, and thus tidal variability would be expected in any acoustic arrivals, even if the identification of those arrivals with any single predicted ray or acoustic mode was impossible. As we have seen, however, we have other reasons for believing that the ray identification is sound.

\section{LOW-Frequency TRAVEL-TIME DATA}

The low-pass-filtered travel times (Fig. 9), i.e., the time series of travel times averaged over each 2- or 4-day transmission period, are used to infer temperature changes averaged along the paths of acoustic propagation [2]-[6]. These largescale temperature changes result from seasonal variations in upper ocean temperature, advection, or normal variations in the air/sea heat flux. Miller et al. [38], for example, have shown that rapid changes with time scales on the order of one month in the large-scale upper ocean heat content are possible; such large-scale variations would be immediately and obviously observed in travel-time time series such as these. The ray travel times are inherently range-averaging and thus are most sensitive to large-scale variations; small length-scale variations are not resolved by these data. An accurate interpretation of the travel-time variations depends on the sampling of the identified ray paths. Except where the time series stops altogether, the acoustic data have adequate sampling in time; the sampling schedule was determined by the MMRP.

\section{A. Receptions at Arrays $\boldsymbol{k}$ and $\boldsymbol{l}$}

The low-frequency travel-time time series for arrays $\boldsymbol{k}$ and $\boldsymbol{l}$ (Fig. 9) show the same general characteristics for all the ray paths: the travel times increased until mid-April 1996, decreased until mid-September 1996, and then increased again until the time series ended in early March 1997. For the northernmost acoustic paths, this annual cycle is observed to be surprisingly smooth, with little evidence of mesoscale variability. The central North Pacific has little eddy variability [39]-[41], and the short space and small time-scale variations

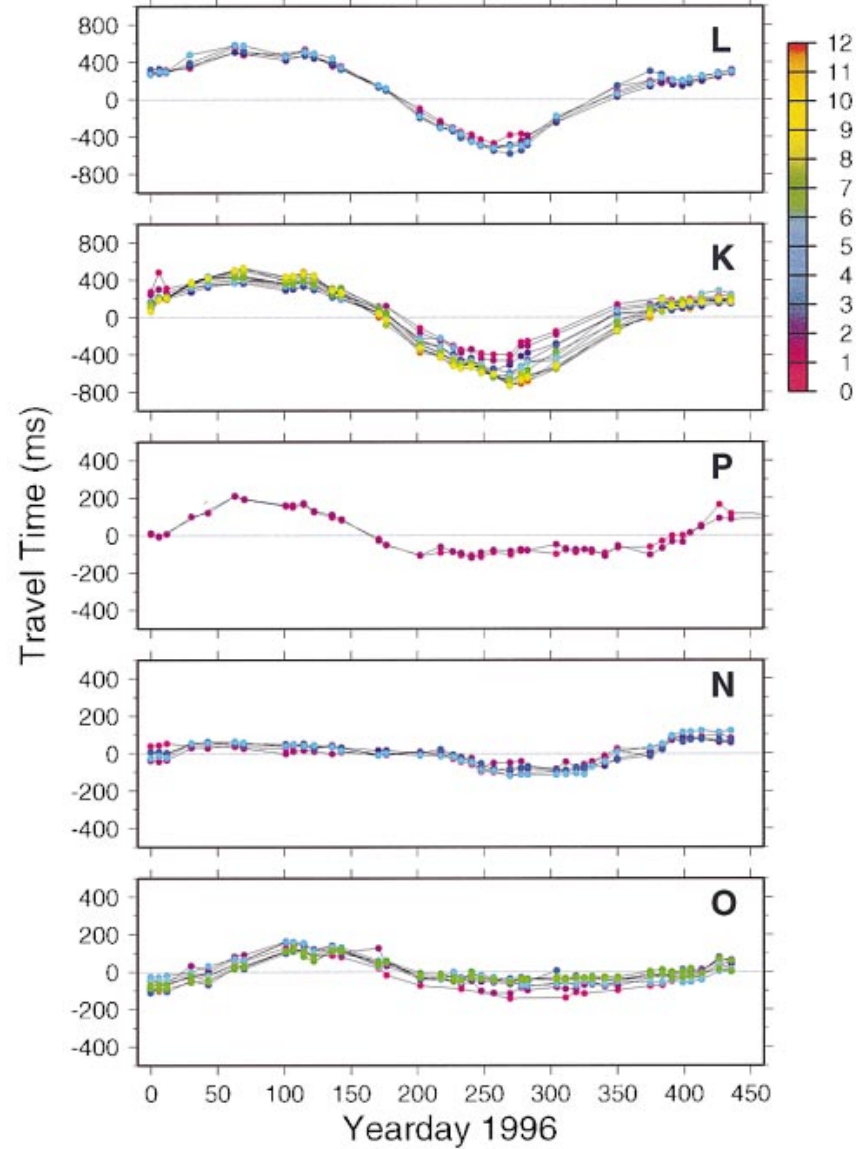

Fig. 9. Low-frequency $(<0.25-1 \mathrm{cpd})$ travel-time variations observed at $\boldsymbol{k}, \boldsymbol{l}, \boldsymbol{n}, \boldsymbol{o}$, and $\boldsymbol{p}$. The time series in each panel are from the various resolved-ray arrivals. An annual cycle is observed, and the change in the dispersal of the arrivals at array $\boldsymbol{k}$ is consistent with the different sampling of the summertime mixed layer by the ray paths. Note that the vertical axis scale of the top two panels is twice that of the others.

are strongly suppressed in the range-averaging acoustic data. The peak to peak variation of this annual cycle in ray travel time over the 5-Mm range can be as large as 1000-1200 ms. Increasing travel times are consistent with a cooling ocean (decreasing sound speed), as might be expected during boreal January. The annual cycle observed in the data results primarily from the formation and erosion of a summertime mixed layer in the North Pacific [6]. In addition, there are suggestions of higher frequency components in the two time series, perhaps indicating the influence of advection or the movement of sharp features such as ocean fronts [1]. The data for array $\boldsymbol{l}$ have occasional gaps caused by an occasional low SNR of unknown origin [see Fig. 2(b)].

In the data obtained from array $\boldsymbol{k}$, the dispersal of the relative travel times for the different rays changes slightly over six months, which suggests that some depth-dependent information may be available. Steeper RSR rays are less influenced by upper ocean changes. Hence, their travel times will show slightly less variation than less inclined rays. As expected, the dispersal of the ray arrivals increases in summertime with the formation of the mixed layer and decreases in the fall or winter months as the upper ocean cools again and becomes more adiabatic. 


\section{B. Receptions at Arrays $\boldsymbol{n}, \boldsymbol{o}$, and $\boldsymbol{p}$}

Interpretation of the low-frequency travel-time variability at arrays $\boldsymbol{n}, \boldsymbol{o}$, and $\boldsymbol{p}$ is complicated by the ray path geometry associated with these data. The ray paths to array $\boldsymbol{o}$, for example, begin as surface reflecting in the region of colder surface waters near California but change to near-surface refracting as they enter warmer subtropical surface waters. This change in ray path sampling is taken into account in the estimation of temperatures. The occasional lack of sampling of nearsurface depths shows the obvious need for complementary data such as those provided by TOPEX/POSEIDON altimetry [1], [42].

The data obtained at receivers $\boldsymbol{n}, \boldsymbol{o}$, and $\boldsymbol{p}$ sample a similar region of the eastern Pacific. However, the three time series are somewhat different; while the annual cycles are apparent, other higher frequency components to the variability are also evident. Excluding the annual cycle, the dominant time scales associated with the variability observed on these paths appears to be a hundred days or more. Thus, the variability does not have the time scales consistent with mesoscale variability. Spiesberger and Metzger [5] previously observed variability that was different between acoustic paths that similarly sampled the eastern Pacific. No explanation is yet available for deviations of the observed time series from the annual cycle.

\section{Comparison to the Levitus Atlas}

The Levitus ocean atlas [25], [26] provides monthly realizations of the Pacific ocean temperature and salinity fields, from which sound speed [27] can be calculated. The monthly travel times for the rays resolved in the ATOC data can be obtained from these sound-speed fields. The simulated monthly travel times (Fig. 10) account for most of the variation in the observed travel times, including the increase in the dispersal of the ray arrivals that occurs in mid to late summer. Indeed, the Levitus simulation predicts that array $\boldsymbol{p}$ will show a stronger annual cycle than arrays $\boldsymbol{n}$ and $\boldsymbol{o}$, as is observed. Of course, the most interesting oceanographic signal is the difference between the Levitus and measured travel-time variations; deviations from the Levitus atlas might occur as a result of phenomena such as El Niño or global warming.

The measured travel times (Fig. 9) are seen to have smoother variation than the Levitus-predicted travel times (Fig. 10). Sound-speed maps derived from the Levitus atlas frequently have points with large unphysical soundspeed anomalies caused by occasional erroneous values of temperature, so that the predicted travel-time variation is not as smooth as might be expected. [Note added in proof: A revised, corrected Levitus atlas has recently been made available.] These anomalies probably cause the gaps in travel times evident in the predictions, which occur when a particular ray is difficult to calculate. The ray predictions become unreliable when the model for sound speed is not smooth. In addition, the Levitus atlas is only as good as the hydrographic database from which it was derived, and this database is inadequate in some regions for an accurate estimate of monthly mean temperature and salinity.

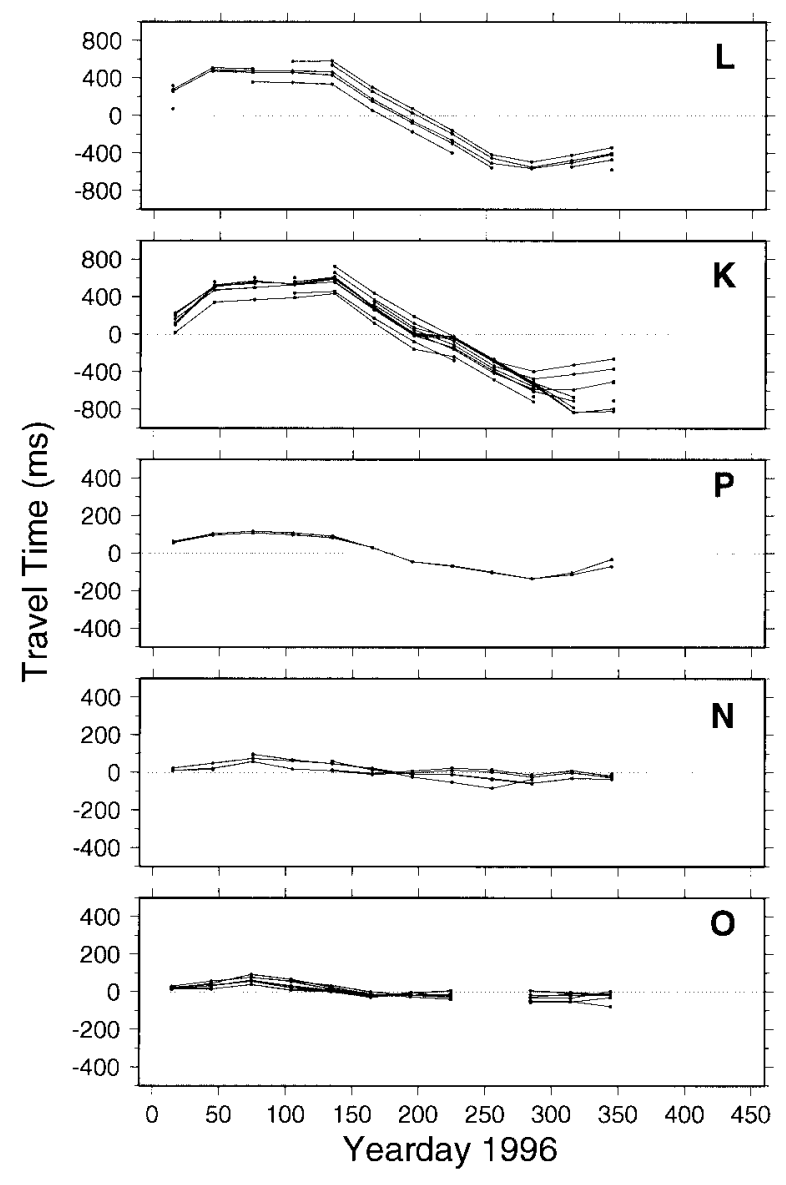

Fig. 10. Low-frequency travel-time variability simulated using the monthly realizations of the Levitus94 ocean atlas to determine monthly sound-speed fields.

\section{DISCUSSION}

This survey of acoustic data obtained using bottom-mounted hydrophone arrays during the ATOC transmissions has shown that, in most cases, these data are adequate for acoustic thermometry. Of the six receivers considered here, five have "trackable" data, and, of these, three have unambiguous ray identifications. The primary complicating factor in these data is the interaction of the acoustic energy with the ocean bottom near the receivers or near the acoustic source. In spite of these complications, several acoustical and oceanographic mysteries are apparent: 1) acoustic arrivals at some arrays appear to occur well into the shadow zone, yet also appear to be stable ray arrivals; 2) variability of SNR is occasionally observed in acoustic data obtained at the 5-Mm range; 3) deviations from a pure sinusoidal annual cycle are observed in the eastern Pacific, e.g., time series obtained at similar arrays in the eastern Pacific vary in slightly different ways, such as peaking at different times; and 4) the measured and predicted travel times at array $l$ surprisingly did not match, although the weak SNR for this particular array suggests this problem may be a bottom interaction, rather than an acoustical propagation, issue. Solving these mysteries will be the next tasks in studying these data.

While the data obtained using the bottom-mounted hydrophone arrays are sometimes problematical, data obtained 
from VLA's [8]-[10] show that clear resolved ray arrivals may be expected even out to $5 \mathrm{Mm}$. The challenge here has been to make sense of and use the bottom-mounted receiver data, which are more easily obtained. Sometimes the data obtained at the bottom arrays are of comparable quality to the VLA data, but often not.

While it might appear that significant variability would be introduced into the acoustical time series by the California current system, this is not the case. Simulations of acoustic transmissions through the California current region using sound-speed fields defined by $20 \mathrm{y}$ of California Cooperative Fisheries Investigations (CalCOFI) hydrographic data [43] gave travel-time variations of only about $\pm 30 \mathrm{~ms}$ [44]. The California current system is primarily shallow and weak. This system is part of North Pacific variability in any case; it is hard to set fixed boundaries around the California current.

The time series of transmissions from Pioneer Seamount stopped in March 1997 because of a break in the cable used to power the acoustic source. Although the cable was repaired in the fall of 1997, this time series unfortunately ended altogether in December 1998 when the 24-month-long marine mammal study ended, and the acoustic source will be removed as required by various permits.

The receptions at $\boldsymbol{k}$ are a remarkable demonstration of the feasibility of 5-Mm-scale ocean acoustic tomography, even though the receptions at other sites may sometimes be complicated by bottom interactions. The remarkably smooth time series of observed travel times show that the thermal variability of the large-scale ocean is quite smooth. Neither altimetric nor hydrographic data have demonstrated such smoothness for reasons inherent to those data types. Altimetric data include the effects of barotropic motions and mass redistribution [1], while hydrographic data are obtained at single points in the ocean, and, thus, suffer from the noise of mesoscale variability and inadequate temporal sampling. The averaging tomographic data uniquely observe the large-scale thermal variations. This paper describes data from the longest transmissions to date for which resolved-ray tomography is shown to be feasible.

\section{ACKNOWLEDGMENT}

The author would like to thank S. Leach, D. Reddaway, S. Weslander, and the U.S. Naval Facility personnel for their skill and dedication in obtaining the time series described in this paper owe their existence.

\section{REFERENCES}

[1] The ATOC Consortium, "Observing ocean climate change: Comparison of acoustic tomography and satellite altimetry with circulation modeling," Science, vol. 281, pp. 1327-1332, 1998.

[2] B. D. Dushaw, "Inversion of multimegameter range acoustic data for ocean temperature," IEEE J. Oceanic Eng., this issue, pp. 216-224.

[3] J. L. Spiesberger, P. J. Bushong, K. Metzger, and T. G. Birdsall, "Basinscale tomography: Synoptic measurements of a 4000-km length section in the Pacific," J. Phys. Oceanogr., vol. 19, pp. 1073-1090, 1989.

[4] J. L. Spiesberger and K. Metzger, "Basin-scale tomography: A new tool for studying weather and climate," J. Geophys. Res., vol. 96, pp. 4869-4889, 1991

[5] _ "Listening for climatic temperature change in the northeast Pacific: 1983-1989," J. Acoust. Soc. Amer., vol. 92, pp. 384-396, 1992.

[6] B. D. Dushaw, P. F. Worcester, B. D. Cornuelle, and B. M. Howe, "Variability of heat content in the central North Pacific in summer 1987 determined from long-range acoustic transmissions," J. Phys. Oceanogr., vol. 23, pp. 2650-2666, 1993.

[7] W. Munk, P. Worcester, and C. Wunsch, Ocean Acoustic Tomography. New York: Cambridge Univ., 1995.

[8] P. F. Worcester, B. D. Cornuelle, J. A. Hildebrand, W. S. Hodgkiss, Jr., T. F. Duda, J. Boyd, B. M. Howe, J. A. Mercer, and R. C. Spindel, "A comparison of measured and predicted broadband acoustic arrival patterns in travel time-depth coordinates at 1000-km range," J. Acoust. Soc. Amer., vol. 95, pp. 3118-3128, 1994.

[9] J. A. Colosi, E. K. Scheer, S. M. Flatt, B. D. Cornuelle, M. A. Dzieciuch, W. Munk, P. F. Worcester, and A. B. Baggeroer, "Comparisons of measured and predicted acoustic fluctuations for a $3250-\mathrm{km}$ propagation experiment in the eastern North Pacific," J. Acoust. Soc. Amer., to be published.

[10] P. W. Worcester, B. D. Cornuelle, M. A. Dzieciuch, W. H. Munk, B M. Howe, J. A. Mercer, R. C. Spindel, J. A. Colosi, K. Metzger, and T. G. Birdsall, "A test of basin-scale thermometry using a large-aperture vertical array at 3250-km range in the eastern North Pacific," J. Acoust. Soc. Amer., to be published.

[11] ATOC Instrumentation Group, "Instrumentation for the acoustic thermometry of ocean climate (ATOC) prototype Pacific Ocean network," Oceans '95, vol. 3, pp. 1483-1500, 1995.

[12] B. M. Howe, "Acoustic thermometry of ocean climate (ATOC): $\mathrm{Pi}$ oneer seamount source installation," Applied Physics Lab., Univ. of Washington, Seattle, WA, APL-UW TM 3-96, 1996.

[13] K. M. Metzger, Jr., "Signal processing equipment and techniques for use in measuring ocean acoustic multipath structures," Ph.D. dissertation, Univ. of Michigan, Ann Arbor, 1983.

[14] W. W. L. Au, P. E. Nachtigall, and J. A. Pawloski, "Acoustic effects of the ATOC signal $(75 \mathrm{~Hz}, 195 \mathrm{~dB})$ on dolphins and whales," J. Acoust. Soc. Amer., vol. 101, pp. 2973-2977, 1997.

[15] A. S. Frankel and C. W. Clark, "Results of low-frequency playback of M-sequence noise to humpback whales, Megaptera novaeangliae, in Hawaii," Can. J. Zool., vol. 76, pp. 521-535, 1998.

[16] A. P. Klimley and S. C. Beavers, "Playback of acoustic thermometry of ocean climate (ATOC)-like signal to bony fishes to evaluate phonotaxis," J. Acoust. Soc. Amer., vol. 104, pp. 2506-2510, 1998.

[17] K. Curtis, B. M. Howe, and J. A. Mercer, "Low frequency ambient sound in the North Pacific: Long time series observations, J. Acous. Soc. Amer., submitted for publication.

[18] J. L. Spiesberger and F. D. Tappert, "Kaneohe acoustic thermometer further validated with rays over $3700 \mathrm{~km}$ and the demise of the idea of axially trapped energy," J. Acous. Soc. Amer., vol. 99, pp. 173-184, 1996.

[19] J. B. Bowlin, J. L. Spiesberger, T. F. Duda, and L. F. Freitag, "Ocean acoustical ray-tracing software RAY," Tech. Rep. WHOI-93-10, Woods Hole Oceanographic Institution, Woods Hole, MA, 1992.

[20] J. L. Spiesberger, "Successful ray modeling of acoustic multipaths over a 3000-km section in the Pacific," J. Acoust. Soc. Amer., vol. 95, pp. 3654-3657, 1994.

[21] National Imagery and Mapping Agency, World Geodetic System 1984 (WGS 84)-Its Definition and Relationships with Local Geodetic Systems, 3rd ed. Washington, DC: National Imagery and Mapping Agency, 1997.

[22] J. G. Dworski and J. A. Mercer, "Hamiltonian 3-D ray tracing in the oceanic waveguide on the ellipsoidal earth," Tech. Rep. APL-UW TR 8929, Applied Physics Lab., Univ. of Washington, Seattle, WA, 1990.

[23] M. Dzieciuch, personal communication, 1998.

[24] S. Levitus, "Climatological atlas of the world ocean," NOAA Prof. Paper, 13, 1982.

[25] S. Levitus, R. Burgett, and T. P. Boyer, World Ocean Atlas 1994, Vol. 3. Salinity, NOAA Atlas NESDIS 3. Washington, DC: U.S. Government Printing Office, 1994.

[26] S. Levitus and T. P. Boyer, World Ocean Atlas 1994, Vol. 4: Temperature, NOAA Atlas NESDIS 4. Washington, DC: U.S. Government Printing Office, 1994

[27] V. A. Del Grosso, "New equation for the speed of sound in natural waters (with comparisons to other equations," J. Acoust. Soc. Amer., vol. 56, pp. 1084-1091, 1974.

[28] P. F. Worcester, B. D. Dushaw, and B. M. Howe, "Gyre-scale reciprocal acoustic transmissions," Ocean Variability and Acoustic Propagation, J. Potter and A. Warn-Varnas, Eds. Norwell, MA: Kluwer, 1991, pp. 119-134.

[29] B. D. Dushaw, P. F. Worcester, B. D. Cornuelle, and B. M. Howe, "On equations for the speed of sound in seawater," J. Acoust. Soc. Amer., vol. 93 , pp. 255-275, 1993.

[30] J. L. Spiesberger, "Is Del Grosso's sound-speed algorithm correct?," $J$. Acoust. Soc. Amer., vol. 93, pp. 2235-2237, 1993. 
[31] B. D. Cornuelle, "Inverse methods and results from the 1981 ocean acoustic tomography experiment," Ph.D. dissertation, M.I.T.-W.H.O.I. Joint Program in Oceanography, WHOI Ref., 83-31, 1983.

[32] J. A. Colosi, S. M. Flatt, and C. Bracher, "Internal-wave effects on 1000$\mathrm{km}$ oceanic acoustic pulse propagation: Simulation and comparison with experiment," J. Acous. Soc. Amer., vol. 96, pp. 452-468, 1994.

[33] G. D. Egbert, A. F. Bennett, and M. G. G. Foreman, "TOPEX/ POSEIDON tides estimated using a global inverse model," J. Geophys. Res., vol. 99, pp. 24-821-24-852, 1994.

[34] B. D. Dushaw, G. D. Egbert, P. F. Worcester, B. D. Cornuelle, B. M. Howe, and K. Metzger, "A TOPEX/POSEIDON global tidal model (TPXO.2) and barotropic tidal currents determined from long-range acoustic transmissions," Prog. Oceanogr., vol. 40, pp. 337-367, 1997.

[35] R. H. Headrick, J. L. Spiesberger, and P. J. Bushong, "Tidal signals in basin scale acoustic transmissions," J. Acoust. Soc. Amer., vol. 93, pp. 790-802, 1993.

[36] B. D. Dushaw, P. F. Worcester, B. D. Cornuelle, and B. M. Howe, "Barotropic and baroclinic tides in the central north Pacific Ocean determined from long-range reciprocal acoustic transmissions," J. Phys. Oceanogr., vol. 25, pp. 631-647, 1995.

[37] B. D. Dushaw and P. F. Worcester, "Resonant diurnal internal tides in the North Atlantic," Geophys. Res. Lett., vol. 25, pp. 631-647, 1998.

[38] A. J. Miller, D. R. Cayan, T. P. Barnett, N. E. Graham, and J. M. Oberhuber, "The 1976-77 climate shift of the Pacific Ocean," Oceanogr., vol. 7, pp. 21-26, 1994

[39] W. J. Emery, "On the geographical variability of the upper mean and eddy fields in the North Atlantic and North Pacific," J. Phys. Oceanogr., vol. 13, pp. 269-291, 1983.

[40] C. K. Shum, R. A. Werner, D. T. Sandwell, B. H. Zhang, R. S. Nerem and B. D. Tapley, "Variations of global mesoscale eddy energy observed from Geosat," J. Geophys. Res., vol. 95, pp. 17-865-17-876, 1990.

[41] C. Wunsch and D. Stammer, "The global frequency-wavenumber spectrum of oceanic variability estimated from TOPEX/POSEIDON altimetric measurements," J. Geophys. Res., vol. 100, pp. 24-895-24-910, 1995.

[42] L.-L. Fu, E. J. Christensen, C. A. Yamarone, M. Lefebvre, Y. Mnard, M. Dorrer, and P. Escudier, "TOPEX/POSEIDON mission overview," J. Geophys. Res., vol. 99, pp. 24-369-24-382, 1994

[43] Anonymous, "Data report: Physical, chemical, and biological data; $\mathrm{Cal}-$ COFI Cruise 8907, CalCOFI Cruise 8908, CalCOFI Cruise 8911," SIO Reference 90-19, May 28, 1990, Univ. California, Scripps Institution of Oceanography, La Jolla, CA, 1990

[44] B. D. Dushaw, unpublished.

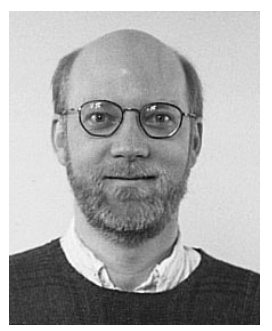

Brian D. Dushaw received the A.B. degree in physics from Occidetal College, Los Angeles, CA, in 1983, the M.A. degree in physics from the University of California at Davis in 1985, and the $\mathrm{Ph} . \mathrm{D}$. degree in oceanography from Scripps Institute of Oceanography, University of California at San Diego, in 1992.

From 1992 to 1994, he was a Postdoctoral Research Scientist at the Applied Physics Laboratory, University of Washington, Seattle, where he is presently an Oceanographer.

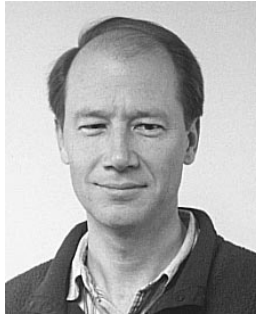

Bruce M. Howe received the B.S. degree in mechanical engineering and the M.S. degree in engineering science, both in 1978, from Stanford University, Palo Alto, CA, and the Ph.D. degree in oceanography in 1986 from the Scripps Institution of Oceanography, University of California, San Diego.

From 1979 to 1981, he was a Research Associate at the Institut für Hydromechanik, Universität Karlsruhe. From 1986 to 1987, he was a Postgraduate Researcher at the Institute for Geophysics and Planetary Physics, University of California at San Diego. He is presently a Senior Oceanographer at the Applied Physics Laboratory, University of Washington, Seattle, and a Research Associate Professor in Oceanography at the University of Washington, Seattle.

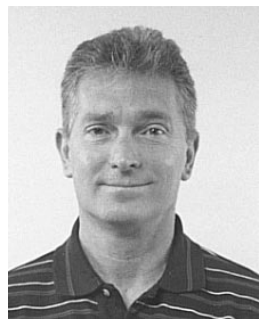

James A. Mercer received the B.S. degree in physics in 1968 and the Ph.D. degree in geophysics in 1983, both from the University of Washington, Seattle.

$\mathrm{He}$ is presently a Principal Physicist at the Applied Physics Laboratory, University of Washington, and a Research Associate Professor in Geophysics at the University of Washington. He is currently an Associate Editor of the U.S. Navy Journal of Underwater Acoustics.

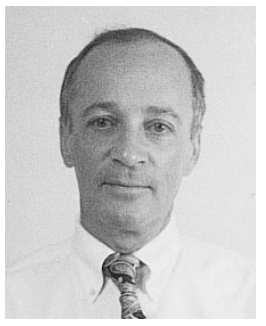

Robert C. Spindel (S'63-M'70-SM'88-F'91) received the B.E. degree in electrical engineering from The Cooper Union, New York, NY, in 1965 and the M.S., M.Phil, and Ph.D. degrees in electrical engineering from Yale University, New Haven, CT in 1966, 1968, and 1971, respectively.

During 1971, he was a Postdoctoral Research Fellow at the Woods Hole Oceanographic Institution, Woods Hole, MA. In 1972, he joined the Scientific Staff of the Institution's Department of Ocean Engineering. He was appointed Chairman of the Department in 1982. In 1987, he joined the University of Washington, Seattle, where he holds professorships in Electrical Engineering and Oceanography and is the Director of the Applied Physics Laboratory.

Dr. Spindel was awarded the A.B. Wood Medal by the British Institute of Acoustics in 1981, the Gano Dunn Award from The Cooper Union in 1988, and the IEEE Oceanic Engineering Society's Technical Achievement Award in 1990. He is a fellow of the Acoustical Society of America and the Marine Technology Society. He served as President of the latter organization from 1983 to 1985, and has been a member of the IEEE Oceanic Engineering Society administrative committee and an Associate Editor of IEEE JouRNAL OF OCEANIC ENGINEERING for many years. He is presently a member of the National Research Council's Naval Studies Board and the Naval Research Advisory Committee. 